\title{
Article \\ Multimodal Sensorimotor Integration of Visual and Kinaesthetic Afferents Modulates Motor Circuits in Humans
}

\author{
Volker R. Zschorlich ${ }^{1, * \mathbb{D}}$, Frank Behrendt ${ }^{2} \mathbb{D}$ and Marc H. E. de Lussanet ${ }^{3}$ (D) \\ 1 Department of Movement Science, University of Rostock, Ulmenstraße 69, 18057 Rostock, Germany \\ 2 Reha Rheinfelden, Research Department, Salinenstrasse 98, CH-4310 Rheinfelden, Switzerland; \\ F.Behrendt@reha-rhf.ch \\ 3 Department of Movement Science, and OCC Center for Cognitive and Behavioral Neuroscience, University of \\ Münster, Horstmarer Landweg 62b, 48149 Münster, Germany; lussanet@uni-muenster.de \\ * Correspondence: volker.zschorlich@uni-rostock.de
}

check for

updates

Citation: Zschorlich, V.R.; Behrendt, F.; de Lussanet, M.H.E. Multimodal Sensorimotor Integration of Visual and Kinaesthetic Afferents Modulates Motor Circuits in Humans. Brain Sci. 2021, 11, 187. https://doi.org/ 10.3390/brainsci11020187

Received: 3 January 2021

Accepted: 1 February 2021

Published: 3 February 2021

Publisher's Note: MDPI stays neutral with regard to jurisdictional claims in published maps and institutional affiliations.

Copyright: (C) 2021 by the authors. Licensee MDPI, Basel, Switzerland. This article is an open access article distributed under the terms and conditions of the Creative Commons Attribution (CC BY) license (https:/ / creativecommons.org/licenses/by/ $4.0 /)$.

\begin{abstract}
Optimal motor control requires the effective integration of multi-modal information. Visual information of movement performed by others even enhances potentials in the upper motor neurons through the mirror-neuron system. On the other hand, it is known that motor control is intimately associated with afferent proprioceptive information. Kinaesthetic information is also generated by passive, external-driven movements. In the context of sensory integration, it is an important question how such passive kinaesthetic information and visually perceived movements are integrated. We studied the effects of visual and kinaesthetic information in combination, as well as isolated, on sensorimotor integration, compared to a control condition. For this, we measured the change in the excitability of the motor cortex (M1) using low-intensity Transcranial magnetic stimulation (TMS). We hypothesised that both visual motoneurons and kinaesthetic motoneurons enhance the excitability of motor responses. We found that passive wrist movements increase the motor excitability, suggesting that kinaesthetic motoneurons do exist. The kinaesthetic influence on the motor threshold was even stronger than the visual information. Moreover, the simultaneous visual and passive kinaesthetic information increased the cortical excitability more than each of them independently. Thus, for the first time, we found evidence for the integration of passive kinaesthetic- and visual-sensory stimuli.
\end{abstract}

Keywords: kinaesthetic; motor neuron; mirror neuron; multimodal integration; proprioception; perception; sensorimotor integration; sensory processes

\section{Introduction}

Sensorimotor control processes of targeted movements in sport and music require effective performance in the integration of different sensory modalities. One aspect of these operations is summarized as multi-sensory integration and has been addressed in various paradigms.

With regard to multimodal information processing, it has been assumed that visual information usually plays a dominant role [1,2], but the visual modality does not always dominate the other senses during cross-modal information processing [3]. Ernst and Bülthoff [4] found that the merging of information is following the principle of maximum likelihood [5,6]. The brain combines information according to least variance and greatest reliability and weighs the information of corresponding sensors to achieve a robust percept and motor control.

One method to investigate the interaction between visual sensory information and motor circuits on a neuronal level is the measure of single neuron activity. This was carried out in the premotor cortices in non-human primates [7] and, more recently, even in the human brain [8]. Nerve cells that associate visual information in the context of movements with the activation of the same motor actions are referred to as mirror neurons. Typical electrophysiological recordings of such mirror neurons in monkeys [7,9-11] have shown a discharge 
both during execution and perception of actions. Since these integration processes involve numerous neurons in the motor cortex, the influence of visual information on motor circuits can also be studied using transcranial magnetic stimulation (TMS) [12-15]. The visual perception of motion activates sensory- and motor-representations in the brain [16-19]. These brain regions are thought to play a central role in movement perception and movement generation, as there is an activation during action execution and during action recognition $[9,20,21]$.

We propose that an analogous functional property exists for kinaesthetic neurons. Kinaesthetic information provides the brain with a sense of movement and position of the limbs in relation to the whole body. Kinaesthetic information comes from proprioceptors, like muscle spindles and Golgi-tendon organs, and other receptors that we are largely unaware of (for review see [22]). With the arrival of coherent information of different modalities, motor circuits respond to a TMS with an elevated motor evoked potential (MEP). The processing of such multimodal information leads to a more precise and differentiated routing of the circuits in motor preparation processes. This, in turn, leads to a more pronounced corticospinal excitability [23]. It has already been shown that visually presented actions can cause such an increase in cortico-spinal excitability [14,15]. On the other hand, on the basis of the hypothesis of dedifferentiation in old age [24-26], it was predicted and found that the process of motor preparation should lead to less pronounced MEP responses from motor cortex stimulation in elderly subjects [27]. For example, in young, non-human primates, it was only possible to initiate a targeted triggering of MEPs after the development of advanced motor skills, which are accompanied by a differentiation of cortical motor structures in ontogenesis [28,29].

An important question is how the different sensory modalities are related, and how they are brought into a common "data format". Putative multi-modality neurons [30-33] in motor-related cortices could take over this task of multisensory-integration projecting to the primary motor cortex. More recently, a significant role in sensorimotor integration has been attributed to the striatum [34]. If kinaesthetic and visual information are processed in the same way during motor preparation we proposed above, both seeing a movement and feeling a passive movement should enhance the corticospinal excitability.

In the present experiment, kinaesthetic sensory information was provided by a motordriven motion of the wrist. The visual information of wrist movement was given by a video clip of a moving hand executing a wrist extension or a wrist flexion movement. Through selective inclusion and exclusion of certain sensory modalities, the effects of visual and kinaesthetic information on motor preparation processes can be analysed. We hypothesize in this study that additional sensory information elevates the MEP amplitudes so that inputs from two different modalities produces motor responses with higher response amplitudes, as in the case of only a single modality or control condition.

\section{Materials and Methods}

\subsection{Subjects}

Twenty healthy participants with a mean age of 28.3 years $( \pm 8.3)$ with no history of neurological disease or upper limb impairment were included. Participants had the opportunity to familiarize themselves with the experiment and with the treatment. In accordance with the Declaration of Helsinki ethical approval for the stimulation experiment was given from the ethics committee of the University of Rostock, Germany. Volunteers gave their written consent to participate in the investigation.

\subsection{Protocol}

A total of 60 stimulations were applied for the three conditions: kinaesthetic in an extension movement (KIN); visual display of an extension movement (VIS); and as the third condition, the combination of visual and kinaesthetic extension afferent information (VIS \& KIN). For the control condition (CC), 20 stimulations were applied. The magnetic stimulation was performed within an interval of minimal $5 \mathrm{~s}$ temporal extent. Volunteers 
were told to feel their wrist joint moving by looking at the monitor with the extending wrist joint in the VIS, KIN, and VIS \& KIN condition. All conditions were supplied in a random order. Coil placement and stimulation period lasted for a total of about $15 \mathrm{~min}$. The CC measurement was conducted in a relaxed state without any movement, while looking on a small cross in the middle of the black screen instead of the displayed hand movement video clip (Figure 1).
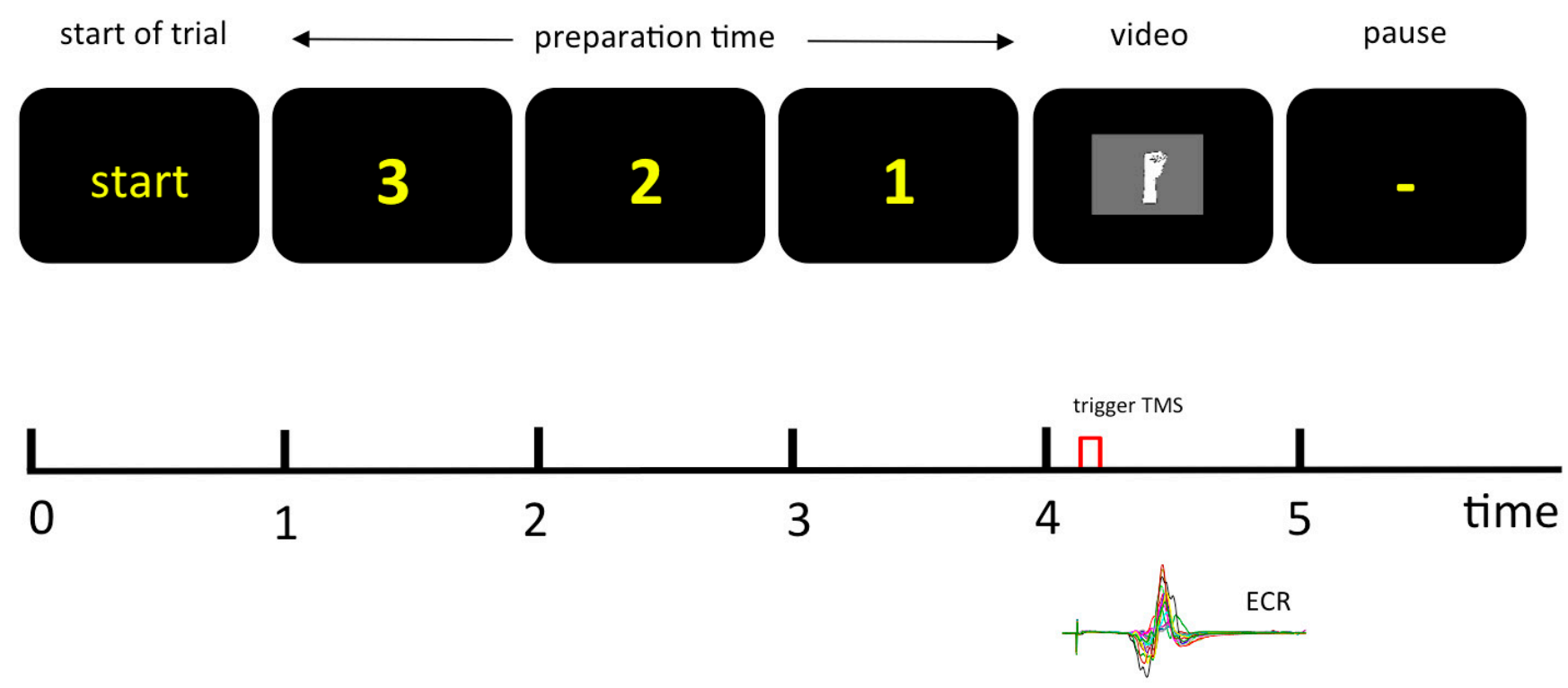

Figure 1. Schematic representation of the experimental set up shows the screen presentation for the different experimental conditions of sensory input. After the presentation of the start signal, there was a 3-s delay before the hand (VIS, VIS \& KIN) was presented. In the kinaesthetic only condition (KIN), a black screen was shown instead. In the control condition (CC), a small fixation cross was shown. TMS was applied in the zero position during moving the wrist from the flexed to the extended position. The EMG (electromyogram) of the extensor carpi radialis muscle (ECR) was measured.

\subsection{Brain Stimulation}

With TMS, it is feasible to show the influence of different sensory input modes on the target-directed motor circuits of the human primary motor cortex [12-15], and it is, therefore, possible to address some aspects of sensorimotor integration. Low-intensity transcranial stimuli $[35,36]$ were delivered slightly above motor threshold. With this method, it is possible to excite already subliminal elevated neurons in the primary motor cortex (M1) above threshold and to release an MEP. With low-intensity magnetic impulses, it is viable to do a readout of the near threshold elevated upper motor neurons. For TMS, a magnetic stimulator R30 MagPro with MagOption (MagVenture, Skovlunde Denmarkformerly Medtronic) and a parabolic coil type MMC-140 were used. A biphasic symmetric pulse of a duration of $280 \mu \mathrm{s}$ was administered for stimulation. A biphasic pulse shows more efficacy in activating neural tissue of the hand area $[37,38]$. The coil was placed over the brain area where the lowest motor threshold could be found for the recorded muscle. Therefore, the stimulation side was about one to two $\mathrm{cm}$ behind the vertex over the right motor cortex with the concave side of the coil was placed to the surface of the skull. The coil was oriented over the right motor cortex. The coil position was kept constant with the help of two adjustable arms (Manfrotto, Feltre, Italy) during the whole experiment. The magnetic gradient of the stimulator was defined as $20 \%$ above the resting motor threshold to get sufficient detectable MEP on the left hand extensor carpi radialis muscle (ECR). The motor threshold was defined as stimulus intensity that produced an MEP of $100 \mu \mathrm{V}$ in three of five trials. The used intensities just marginally above motor threshold were chosen for better detection the modulation effects of different senses on the motor preparatory processes. It could be shown that stimulation with $1.2 \times$ resting motor 
threshold is suitable $[39,40]$. The magnetic gradient in all trials lies therefore in the range between $45-75 \mathrm{~A} / \mu \mathrm{s}$.

\subsection{Electromyography (EMG)}

The TMS elicited motor evoked potentials were recorded with a custom made differential amplifier with an input resistance of $16 \mathrm{~g} \Omega$ and a bandwidth of 1 to $1000 \mathrm{~Hz}$. The gain was chosen with a factor of 1000. Before calculation, EMG signals were high-pass filtered by a digital first-order Butterworth filter with a cut-off frequency of $1 \mathrm{~Hz}$ [41]. The MEP responses were registered with two $\mathrm{Ag}-\mathrm{AgCl}$ cup electrodes (Hellige baby-electrodes; $\mathrm{GE}$ medical systems, Milwaukee, WI, USA) with an electrode surface area of $3 \mathrm{~mm}^{2}$ and were placed with a distance of $1 \mathrm{~cm}$ longitudinally over the belly of the extensor carpi radialis muscle. The skin preparation before electrode application was carried out with alcohol, and the hairs were removed prior to skin abrasion [42].

The skin impedance at $30 \mathrm{~Hz}$ was always lower than $\mathrm{Z}=10 \mathrm{k} \Omega$. For conductance, an electrode gel (Parker Laboratories, Fairfield, CT, USA) was used. Electrodes and twisted cables were fixed with self-adhesive tape on the skin. As reference, electrode served an ECG-limb-clamp fixed at the upper arm located at the $\mathrm{m}$. biceps. Muscle relaxation was strongly recommended and monitored visually over the whole experiment (Figure 2). MEPs were discarded offline whenever background EMG amplitude higher than $50 \mu \mathrm{V}$ was detectable in a time-window before $300 \mathrm{~ms}$ to movement onset. These events indicate a voluntary muscular activation, which has a prominent impact on MEP amplitudes [43]. The MEP were quantitatively evaluated as peak-to-peak amplitudes (MEPpp) [44,45].
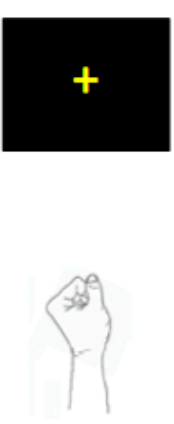

CC
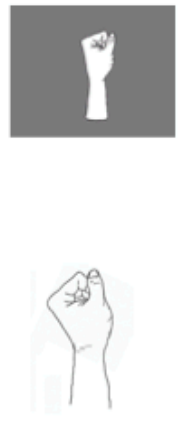

VIS

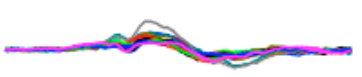

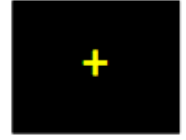

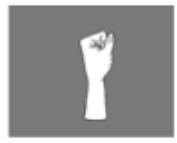

A

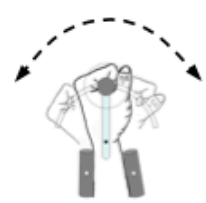

KIN

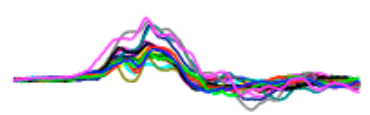

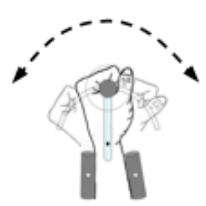

B

VIS \& KIN C

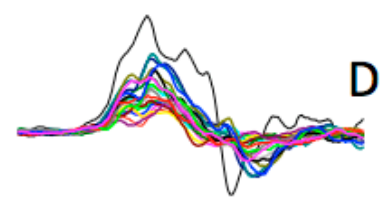

Figure 2. Representative trials of one subject illustrate the MEP of the extension directed movement. The different conditions represent the MEP response of the extensor carpi radialis at the control condition (CC), the visual wrist extension perception (VIS), the merely kinematic condition (KIN), and the coupled visual and kinematic wrist extension condition VIS \& KIN (right). All MEPs have the same scale-units. Calibration bar: $0.5 \mathrm{mV}, 10 \mathrm{~ms}$. (A) Screen, (B) Manipulandum, (C) Condition, (D) MEP.

\subsection{Visual Stimuli}

The hand in the presented animated drawing moved in the experimental KIN condition from the neutral position $\left(0^{\circ}\right)$ to an extension position $\left(-30^{\circ}\right)$ of the wrist joint with an angular velocity of $62.5^{\circ} / \mathrm{s}$ and subsequent duration of $480 \mathrm{~ms}$. At this wrist extension position, the motor stopped, and a wait state of $200 \mathrm{~ms}$ followed. From this hand-extension position $\left(-30^{\circ}\right)$, the hand was moved to a flexion position of $+30^{\circ}$ with the same angular-velocity of $62.5^{\circ} / \mathrm{s}$ and a phase duration of $960 \mathrm{~ms}$ for the flexion whole 
movement (Figure 3). The movement executions carried out before the actual extension movement served for embodiment or synchronization of the afferents. The following extension movement-relevant for the measurement-started from this $+30^{\circ}$ position of the wrist and then moved with a speed of $62.5^{\circ} / \mathrm{s}$ into the extension.
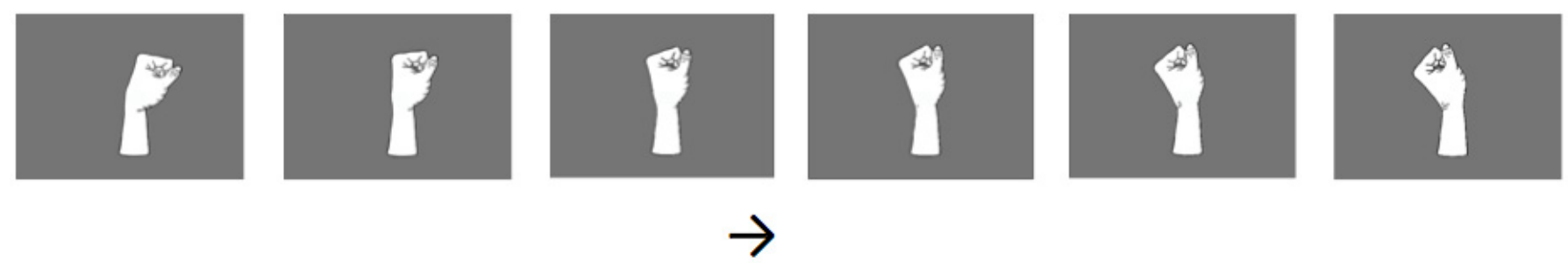

Figure 3. Screenshots of the hand in extension movement clip presented to the participants in the conditions VIS and VIS \& KIN.

During this extension movement, the stimulation was administered exactly at $0^{\circ}$ to keep the corticospinal excitability independent from Ia spindle length [46]. The stimulation happened exactly $480 \mathrm{~ms}$ after starting the passive movement in the extension direction so that visual and kinaesthetic afferents could both reach the motor cortex. After a wait state of $200 \mathrm{~ms}$ in the extension position $\left(-30^{\circ}\right)$, the hand moved to the neutral position and stopped there, and in the next randomized stimulation condition VIS, KIN, or VIS \& KIN can start. The visual demonstrated movement is exactly the same as the rotary actuator movement. The embodiment of the hand movement was achieved by giving the volunteers the opportunity of a sufficiently long preparation (minimal three minutes) for the stimulating conditions by visual presented as well as executed motions of the hand. In all conditions, the participants were instructed to focus both on the feeling of the passive moving hand and on the moving hand on the video screen. For the visual stimulation in the VIS and in the VIS \& KIN condition, the subjects were shown a video animation of an artificial hand motion on a monitor.

A stimulation at the view on the centre cross of the monitor was recorded in the CC and KIN condition. The control condition should help to exclude a possible modulation effect due to changes in attention. For this purpose, a small cross was presented in the middle of the monitor. The distance between the forehead-rest to the monitor was $110 \mathrm{~cm}$, and the display had an image size of $33^{*} 24 \mathrm{~cm}$ (about $18^{\circ}$ angle of view).

\subsection{Kinaesthetic Stimuli}

The kinaesthetic perception of the wrist motion was induced by passive driven limb movement. The subject grasped a handle with the left hand without any muscle activity and rests on a moveable support, while the lower arm was fixed with a cast-construction (Figure 4). The centre alignment between extension and flexion was defined in a relaxed position where the extensor carpi radialis has no muscle activities. Subjects were sitting upright on a chair in front of the motor-driven wrist flexion-extension machine. The left arm rested in a comfortable abduction of the upper arm, and the forearm supported in a relaxed position between pronation and supination. The head of the volunteer was stabilized with a forehead-chin rest to reduce head-to-coil movements. The left arm was bent with about 90 degree at the elbow joint, while the dominant (right) hand rested unrestrained on the table. 


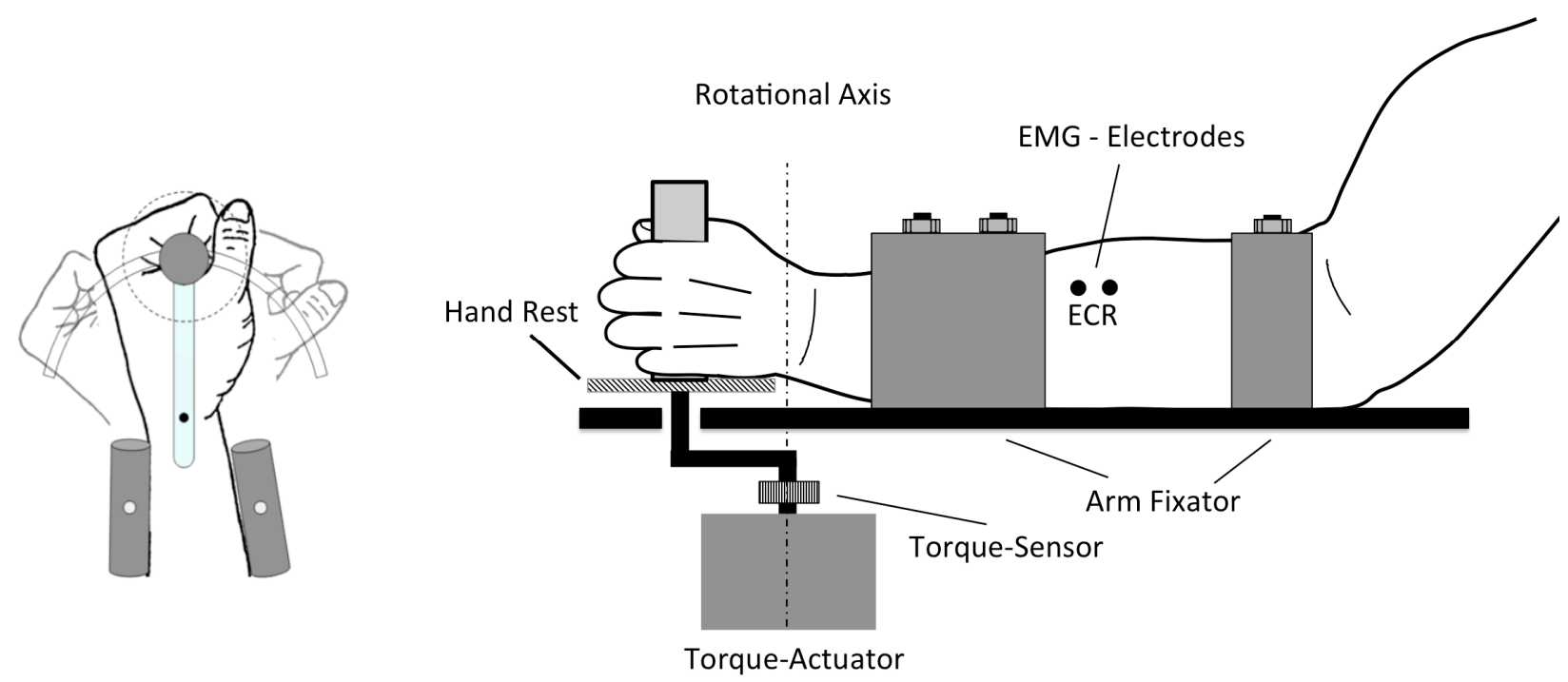

Figure 4. The graphical representation of the flexion-extension machine for wrist movement shows a rotary motor driven lever, a hand rest (dotted circle on the right) and a forearm rest, and the moving hand grip. Electrodes were placed over the extensor carpi radialis (ECR).

The left-hand wrist joint movement was provided by a computer controlled brushless stepper motor (Copley Controls, Canton, MA 02021, U.S.A. type 145ST4M with 500 rpm). The rotary actuator (145ST4M, ALXION, Colombes, France) was controlled by a Copley Xenus servo controller (type XTL-230-36/18-R) from the home position at neutral zero of the wrist. The moving of the crank arm covers an angle of 30 degrees ( $0.5235 \mathrm{rad})$ to maximum deflection. The speed of the crank arm had an angular velocity of $62.5 \mathrm{deg} / \mathrm{s}$ $(1.09 \mathrm{rad} / \mathrm{s})$ of the wrist joint extension or flexion. The given angular velocity was achieved in less than $10 \mathrm{~ms}$. The resolution of the resolver was 98,260 steps for one revolution $(2 \pi \mathrm{rad})$.

To avoid injury, the range of motor movement was mechanically limited to $\pm 45^{\circ}$, and a rapid shutdown was ensured for both the experimenter and the subjects. Care was taken to offer the stimuli in a synchronous manner, otherwise the merging to a coherent percept could be disrupted or perturbed and a kind of de-afferents emerge [47]. The phase difference between the video clip and the torque actuator was less than one display frame throughout the complete movement sequence. In the crossmodal condition, the passive movement was coupled and computer-controlled to a video sequence of the mentioned wrist movement. It was carefully controlled that the machine induced motion resulted only in an extension/flexion of the wrist, and no movement took place on the forearm. The subject's forearm and the actuator were hidden under a curtain. The visual demonstration was directly coupled to the actuator supported passive wrist movement with the same movement duration and angular velocity of the actuator supported movement.

\subsection{Measurement and Data Processing}

All data were sampled simultaneously with a 12 bit analog-digital converter (DAQCard 6024 National Instruments, Austin, TX, USA) at a sampling rate of 10,000/s. DIAdem (National Instruments, Austin, TX, USA) was used for data acquisition and further signal processing.

\subsection{Statistics}

Statistical analysis was performed using SPSS version 22.0 (SPSS Inc., Chicago, IL, USA) for windows. Peak-to-peak data (MEP $\mathrm{pp}$ ) of the motor evoked potentials were calculated. This procedure was used to get a measure of corticospinal excitability. The absolute difference between the maximum and minimum value is expressed as the value of individual MEP. 
An analysis of variance (ANOVA) for repeated measurement was calculated to test for significant differences of the experimental conditions. A post-hoc test was applied to test the significant difference between the demonstrated visual extension movement (VIS), the kinaesthetic extension movement (KIN), the third condition of the synchronized combination of visual and kinaesthetic information (VIS \& KIN), and the control condition (CC). The LSD correction was applied for multiple pairwise comparison. For correction, in this test, in contrast to the simple paired comparison, the variances are calculated over all groups. The significance level was set to $p<0.05$. The Greenhouse-Geisser coefficient $(\varepsilon)$ was employed to correct the degrees of freedom.

\section{Results}

In the current experiment, the ANOVA for repeated measurements shows a significant difference across the four conditions $\left(F(1.25,23.88)=14.36_{\varepsilon=0.42} ; p<0.000, \eta_{\mathrm{p}}{ }^{2}=0.43\right)$. The lowest MEP values $(0.49 \mathrm{mV} \pm 0.33 \mathrm{mV})$ were measured in the control condition (CC), in which the test subjects only had to fix a small, stationary character in the middle of a black screen.

Depending on the offered modes of the movement-associated afferents, the MEPs were elevated. During observation of the wrist extension movement on the screen (VIS), the evoked MEP responses of the extensor carpi radialis muscle were larger as in the CC. With the VIS condition, we found the excitability of the MEPs by $0.65 \pm 0.41 \mathrm{mV}$ peak-to-peak values. In the kinaesthetic condition (KIN), the MEPs were elevated further and were larger than in the visual condition (VIS). The KIN condition showed an excitability of the MEPs by $1.13 \pm 0.89 \mathrm{mV}$ peak-to-peak values.

Coupled kinaesthetic information and visual information for the extension movement were measured in the fourth condition (VIS \& KIN). In the coupled condition, VIS \& KIN, a further increase of the MEPs by $1.31 \pm 0.89 \mathrm{mV}$ peak-to-peak values appeared. The simultaneous observation of a wrist extension and kinaesthetic information of the passive extension in the VIS \& KIN condition enhances the elicited MEPs compared to each solitary afferents and the CC (Figure 5).

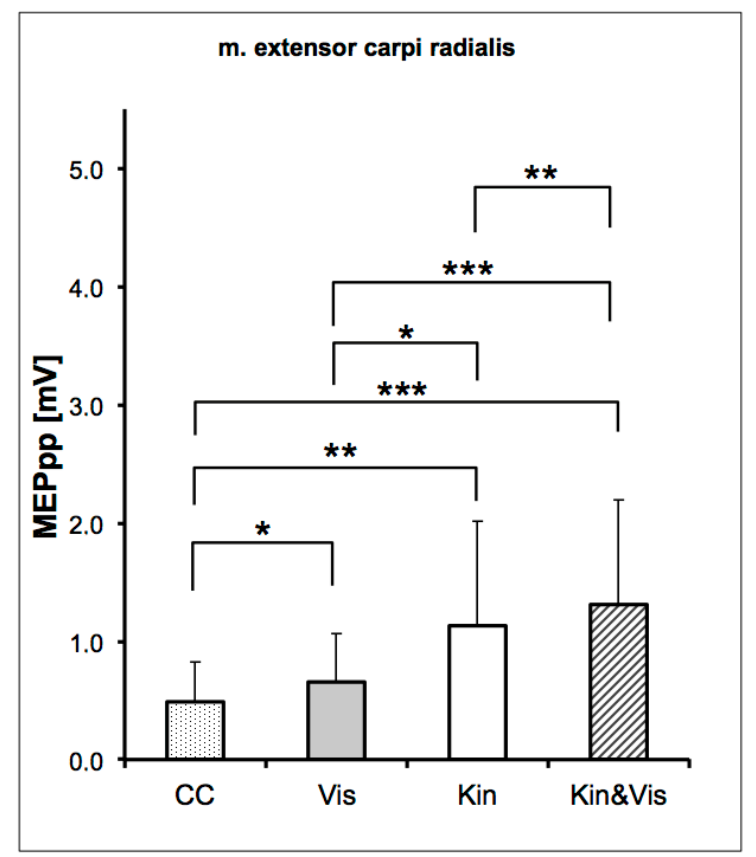

Figure 5. Mean MEP $( \pm S D)$ across subjects, as a function of the four experimental conditions. Post-hoc comparisons of the MEP between all conditions shows significant differences. The MEP amplitudes shows an accumulation over the three different movement related modalities. The MEP amplitudes were presented as the mean \pm standard deviation (SD). Significant differences in the MEP are presented with $*<0.05,{ }^{* *} p<0.01$, and ${ }^{* * *} p<0.001$. 
The LSD (least significant difference) post-hoc test for the pairwise comparison of differences between the factors showed for a significant difference all conditions. The results of the paired comparison for each condition are presented in Table 1 . The greatest difference was detected between the CC and the VIS \& KIN condition. A dominant influence of kinaesthetic and visual motor information on motor preparation is evident. In all subjects, we found a modulatory effect of the sensory integration on the corticospinal excitability.

Table 1. This table shows the post hoc results of the LSD pairwise comparisons between the three stimulation conditions and the control condition. We found significant differences for all comparisons. The LSD Test is based on the two-sample $t$-test. ${ }^{*} p<0.05,{ }^{* *} p<0.01$, and ${ }^{* * *} p<0.001$.

\begin{tabular}{|c|c|c|c|}
\hline Condition & Control & Visual & KIN \\
\hline VIS & $\begin{array}{c}0.015687 \\
*\end{array}$ & & \\
\hline KIN & $\underset{* *}{0.001596}$ & $\begin{array}{c}0.015454 \\
*\end{array}$ & \\
\hline VIS \& KIN & $\underset{* * *}{0.000114}$ & $\underset{* * *}{0.00081}$ & $\begin{array}{c}0.004782 \\
* *\end{array}$ \\
\hline
\end{tabular}

\section{Discussion}

In the present TMS study, we explored the multimodal visual-proprioceptive interaction during the perception of a passive movement of the observer's own hand. The data show that the evoked responses in the bimodal condition were significantly higher than in both unimodal conditions alone. The finding suggests that bimodal action perception has an additive influence, resulting in a more pronounced response to TMS when both modalities are presented simultaneously.

Nearly all events that we are exposed to every day presumably entail more than a single information modality and are thus of a multimodal character [48]. It is commonly accepted that a single human information-processing system alone is not capable of perceiving an event accurately enough in all circumstances and that an extensive perception can only be achieved by the integration of multiple sources of sensory information $[4,49]$. Accordingly, several sources of information are permanently being combined, further processed, and interpreted based on prior knowledge and experience. Classically, the visual perception was often considered the dominant one [50], even independent of others, but there have long been contradictory results [51]. The sense of movement and position of our body or limbs, which is referred to as kinaesthesia [52], relies on proprioceptive afferents. This afferent information interacts with other senses such as vision in the perception process [53]. It was recently confirmed in a study on the contributions of visual and proprioceptive afferents to the perception of a passive arm displacement in virtual reality that this process indeed involves non-visual signals and also that the latter interact with visual signals [54]. In an investigation of mental imagery on neuronal circuits of motor processing, it was found [55] that only kinaesthetic imagery, but not visual imagery, facilitates motor neurons in M1. This supports our results that kinaesthetic information is more effective than visual information in motor control processes. Moreover, Giroux et al. [54] reported that the interaction of the modalities had a strengthening effect on the vividness of the perception of the passive arm movement. This is in line with our results despite the fact that the authors did not test for the corticospinal excitability during the perception of the arm displacement but assessed speed and duration of the perceived movement verbally rated by the participants.

In a different experiment, also using TMS, it was found that there is an additive interaction of sound and sight during action observation [56]. Here, the authors used unimodal visual, unimodal auditory, or both kinds of stimuli combined of hand action and also found a response increase in the multimodal condition. From the results it was concluded that there are likely no different kinds of action representations, i.e., a single representation for 
every modality, but rather shared action representations resulting in stronger responses if stimuli are perceived simultaneously and congruently. Our results support the hypothesis that action representations themselves comprise integrated multimodal information leading to an enhanced response to TMS in case action perception is multimodal and therefore more reliable.

The present study shows that kinaesthetic information affects motor circuits in M1. This means that motor nerve cells exist in M1, which connects kinaesthetic information with the associated excitatory motor structures. On a neuronal level, the influence of visual movement information to the premotor cortex has been known already for over two decades [7]. It is therefore likely that significant portions of the processes of sensorimotor integration, which also pertains to cross-modal processing, are carried out putative in the premotor cortex (PMC) and M1 area. Strick and colleagues $[57,58]$ already proposed that different input modalities in different locations of M1 represent task demands of high-level sensorimotor integration. This integration process may lead to a coherent percept. From studies of non-human primates [30-32], it was supposed that sensorimotor integration is caused by multimodal neurons. Trimodal neurons in the ventral premotor cortex (PMv) were proposed [30], and Makin et al. [33] proposed involved trimodal neurons in PMC and intra-parietal sulcus (IPS) where visual, tactile, and proprioceptive afferents are integrated within one neuron. More recently, experiments found further brain areas, such as the lateral prefrontal cortex (IPFC) and the intraparietal sulcus (IPS), that provide resources for specialized motor control in dance and music [59]. An additional spinal contribution to the modulation of the MEPs cannot be completely ruled out, because a modulated discharge rate of spindle afferents may be crucial when the muscle is progressively lengthened [60-62]. However, it does not seem to be fully clear on which cortical level the convergence of the visual and proprioceptive input takes place. It has been proposed before that multisensory integration takes place at multiple sites within the nervous system [63-65].

It is conceivable that the different inputs are converging before being referenced to frontal mirror areas or M1, as proposed by the results of Barraclough et al. [66]. They identified neurons in the superior temporal sulcus (STS), which potentially form multisensory representations of perceived actions. A study on nonhuman primates also found neurons that exhibit signs of multisensory interactions with super-additive or sub-additive response summation located in the superior temporal region and spatially clustered [67]. In addition, several studies using functional magnetic resonance imaging (fMRI) in humans and nonhumans identified regions in the premotor cortex $[31,68]$ or posterior parietal cortex [69] with clusters of neurons also exhibiting polysensory responses, which might be involved in the integration of multimodal information about action. Furthermore, in animal studies, parts of the midbrain, i.e., deeper laminae of the superior colliculus, have been found to contain multisensory neurons of all possible combinations [48,70]. Thus, the superior colliculus was described as a primary site for the integration of converging inputs from multiple sources but not as a reflection of the multisensory integration process [71]. It is itself in so far not automatically capable of integrating these multiple sensory inputs but obviously relies on the projection from the association cortex for that purpose [71].

It was proposed that response enhancement is a general property of multisensory integration [72]. The fact that we found an additive multisensory enhancements speaks in favour of true multisensory integration. However, the interpretation of cumulative multisensory responses and the role of movement related signals is still discussed [73]. It has been suggested that superadditive responses should exceed additive responses reflecting the activity of neighbouring neurons of unisensory character, as multisensory response interactions were found on a cellular level to be more a multiplicative than a summative change in activity [74,75].

The meaning of cross-modal sensorimotor integration for motor control is obvious. However, the exact function of kinaesthetic information processing is currently still not completely understood. A mirror-like functioning of the kinaesthetic system might indeed be conceivable if one follows the extended mirror system concept of Rizzolatti et al. [76]. 
For example, kinaesthetic training is common in sports such as dance and tennis, when the trainer provides the "feel" of the correct posture and movement by manually guiding the leg or hand.

One part of the kinaesthesis is the contribution of sensors as Golgi tendon organ, cutaneous stretch receptors, and the muscle spindle receptor afferents to the sensory cortex. In the present study, we are interested specifically in the importance of different information in motor control. Certainly, one can note that the kinaesthetic information is of considerable significance to movement execution and motor control. A disturbance of kinaesthesia has an obvious effect on the execution quality and precision of movement. Both need an undisturbed awareness of the peripersonal space, which is the space within reach. As more recently proposed, there are different spatial representations as to the result of motor interaction with the environment depending on the different effector properties [77]. It can be assumed that the emergence of these representations relies on multimodal sensory input. In this context, it has been found that the core part of the cortex involved in the encoding process of the peripersonal space is premotor area F4 [78]. Further, the ablation of the ventral part of the premotor cortex in a study with monkeys resulted in a so-called peripersonal neglect [79], which in turn hints at disturbed integrative processing of the different modalities including kinaesthetic information.

The cross-modal interaction between extero- and proprio-feedback is used to optimize information for motor control. In our experiment, there is some evidence that kinaesthetic information about limb movement, provided by a motor-driven wrist flexion-extension machine, has a greater influence on the task-specific motor circuits than the visual information about the same movement.

\section{Conclusions}

In conclusion, multimodal sensory integration is fundamentally important for motor control. The present data complement the current view of the neural basis of the integration process within the cerebral motor circuits. In our experiment, we investigated the link between two different input modalities, i.e., visual and kinaesthetic information, and the influence of its combination on the motor outcome. The study provides evidence that the motor system excitability is significantly enhanced in subjects that perceive simultaneous information of both modalities about the movement. As the excitatory corticospinal drive was less enhanced when only a single information modality was provided, this hints at an information-specific modulation of corticospinal excitability. The results suggest the existence of "kinaesthetic motoneurons" that respond to kinaesthetic information induced even solely by passive movements. It furthermore supports the assumption that the process of merging multimodal information including kinaesthetic input is a general characteristic of the motor system.

Author Contributions: Conceptualization: V.R.Z. and F.B.; methodology: V.R.Z., F.B., and M.H.E.d.L.; writing - review and editing: V.R.Z., F.B., and M.H.E.d.L. All authors contributed to the analysis and interpretation of the data. All authors have read and agreed to the published version of the manuscript.

Funding: This research received no external funding.

Institutional Review Board Statement: The study was conducted according to the guidelines of the Declaration of Helsinki, and approved by the Institutional Ethics Committee of the University Medicine Rostock (No. A 2016-0138).

Informed Consent Statement: Informed consent was obtained from all subjects involved in the study.

Data Availability Statement: The data presented in this study are available on request from the corresponding author.

Acknowledgments: The authors are indebted to Norbert Wolff and Andreas Mattke for their technical support and building the wrist machine. 
Conflicts of Interest: The authors M.H.E.d.L. and F.B. declare no conflict of interest. V.R.Z. is a member of the editorial board of "Brain Sciences"-Systems Neuroscience.

\section{References}

1. Rock, I.; Victor, J. Vision and touch: An experimentally created conflict between the two senses. Science 1964, 143, 594-596. [CrossRef]

2. McGurk, H.; MacDonald, J. Hearing lips and seeing voices. Nature 1976, 264, 746-748. [CrossRef]

3. Shams, L.; Kamitani, Y.; Shimojo, S. Illusions: What you see is what you hear. Nature 2000, 408, 788. [CrossRef]

4. Ernst, M.O.; Bülthoff, H.H. Merging the senses into a robust percept. Trends Cogn. Sci. 2004, 8, 162-169. [CrossRef]

5. Van Beers, R.J.; Sittig, A.C.; van der Gon Denier, J.J. How humans combine simultaneous proprioceptive and visual position information. Exp. Brain Res. 1996, 111, 253-261. [CrossRef]

6. Van der Kooij, K.; Brenner, E.; van Beers, R.J.; Schot, W.D.; Smeets, J.B.J. Alignment to natural and imposed mismatches between the senses. J. Neurophysiol. 2013, 109, 1890-1899. [CrossRef]

7. Di Pellegrino, G.; Fadiga, L.; Fogassi, L.; Gallese, V.; Rizzolatti, G. Understanding motor events: A neurophysiological study. Exp. Brain Res. 1992, 91, 176-180. [CrossRef]

8. Mukamel, R.; Ekstrom, A.D.; Kaplan, J.; Iacoboni, M.; Fried, I. Single-neuron responses in humans during execution and observation of actions. Curr. Biol. 2010, 20, 750-756. [CrossRef]

9. Gallese, V.; Fadiga, L.; Fogassi, L.; Rizzolatti, G. Action recognition in the premotor cortex. Brain 1996, 119, 593-609. [CrossRef]

10. Umilta, M.A.; Kohler, E.; Gallese, V.; Fogassi, L.; Fadiga, L.; Keysers, C.; Rizzolatti, G. I know what you are doing: A neurophysiological study. Neuron 2001, 31, 155-165. [CrossRef]

11. Dushanova, J.; Donoghue, J. Neurons in primary motor cortex engaged during action observation. Eur. J. Neurosci. 2010, 31, 386-398. [CrossRef]

12. Fadiga, L.; Buccino, G.; Craighero, L.; Fogassi, L.; Gallese, V.; Pavesi, G. Corticospinal excitability is specifically modulated by motor imagery: A magnetic stimulation study. Neuropsychologia 1999, 37, 147-158. [CrossRef]

13. Strafella, A.P.; Paus, T. Modulation of cortical excitability during action observation: A transcranial magnetic stimulation study. Neuroreport 2000, 11, 2289-2292. [CrossRef]

14. Alaerts, K.; Senot, P.; Swinnen, S.P.; Craighero, L.; Wenderoth, N.; Fadiga, L. Force requirements of observed object lifting are encoded by the observer's motor system: A TMS study. Eur. J. Neurosci. 2010, 31, 1144-1153. [CrossRef]

15. Behrendt, F.; de Lussanet, M.H.E.; Zentgraf, K.; Zschorlich, V.R. Motor-evoked potentials in the lower back are modulated by visual perception of lifted weight. PLoS ONE 2016, 11, e0157811. [CrossRef]

16. Buccino, G.; Binkofski, F.; Fink, G.R.; Fadiga, L.; Fogassi, L.; Gallese, V.; Seitz, R.J.; Zilles, K.; Rizzolatti, G.; Freund, H.J. Action observation activates premotor and parietal areas in a somatotopic manner: An fMRI study. Eur. J. Neurosci. 2001, 13, 400-404. [CrossRef]

17. Saygin, A.P.; Wilson, S.M.; Hagler, D.J.; Bates, E.; Sereno, M.I. Point-light biological motion perception activates human premotor cortex. J. Neurosci. 2004, 24, 6181-6188. [CrossRef]

18. de Lussanet, M.H.E.; Fadiga, L.; Michels, L.; Seitz, R.J.; Kleiser, R.; Lappe, M. Interaction of visual hemifield and body view in biological motion perception. Eur. J. Neurosci. 2008, 27, 514-522. [CrossRef]

19. Michels, L.; Kleiser, R.; de Lussanet, M.H.E.; Seitz, R.J.; Lappe, M. Brain activity for peripheral biological motion in the posterior superior temporal gyrus and the fusiform gyrus: Dependence on visual hemifield and view orientation. Neuroimage 2009, 45, 151-159. [CrossRef]

20. Rizzolatti, G.; Sinigaglia, C. The functional role of the parieto-frontal mirror circuit: Interpretations and misinterpretations. Nat. Rev. Neurosci. 2010, 11, 264-274. [CrossRef]

21. Jeannerod, M. Neural simulation of action: A unifying mechanism for motor cognition. Neuroimage 2001, 14, S103-S109. [CrossRef]

22. Proske, U.; Gandevia, S.C. The kinaesthetic senses. J. Physiol. 2009, 587, 4139-4146. [CrossRef]

23. Qi, F.; Nitsche, M.A.; Zschorlich, V.R. Interaction between transcranial random noise stimulation and observation-execution matching activity promotes motor cortex excitability. Front. Neurosci. 2019, 13, 69. [CrossRef]

24. Heuninckx, S.; Wenderoth, N.; Swinnen, S.P. Systems neuroplasticity in the aging brain: Recruiting additional neural resources for successful motor performance in elderly persons. J. Neurosci. 2008, 28, 91-99. [CrossRef]

25. Carp, J.; Park, J.; Hebrank, A.; Park, D.C.; Polk, T.A. Age-related neural dedifferentiation in the motor system. PLoS ONE 2011, 6, e29411. [CrossRef]

26. Bernard, J.A.; Seidler, R.D. Evidence for motor cortex dedifferentiation in older adults. Neurobiol. Aging 2012, 33, 1890-1899. [CrossRef]

27. Reuter, E.-M.; Behrens, M.; Zschorlich, V.R. Age-related differences in corticomotor facilitation indicate dedifferentiation in motor planning. Exp. Gerontol. 2015, 65, 79-84. [CrossRef]

28. Flament, D.; Hall, E.; Lemon, R. The development of cortico-motoneuronal projections investigated using magnetic brain stimulation in the infant macaque. J. Physiol. 1992, 447, 755-768. [CrossRef]

29. Olivier, E.; Edgley, S.A.; Armand, J.; Lemon, R.N. An electrophysiological study of the postnatal development of the corticospinal system in the macaque monkey. J. Neurosci. 1997, 17, 267-276. [CrossRef] 
30. Graziano, M.; Gandhi, S. Location of the polysensory zone in the precentral gyrus of anesthetized monkeys. Exp. Brain Res. 2000, 135, 259-266. [CrossRef]

31. Bremmer, F.; Schlack, A.; Shah, N.J.; Zafiris, O.; Kubischik, M.; Hoffmann, K.-P.; Zilles, K.; Fink, G.R. Polymodal motion processing in posterior parietal and premotor cortex: A human fMRI study strongly implies equivalencies between humans and monkeys. Neuron 2001, 29, 287-296. [CrossRef]

32. Maravita, A.; Iriki, A. Tools for the body (schema). Trends Cogn. Sci. 2004, 8, 79-86. [CrossRef]

33. Makin, T.R.; Holmes, N.P.; Ehrsson, H.H. On the other hand: Dummy hands and peripersonal space. Behav. Brain Res. 2008, 191, 1-10. [CrossRef]

34. Lee, C.R.; Yonk, A.J.; Wiskerke, J.; Paradiso, K.G.; Tepper, J.M.; Margolis, D.J. Opposing influence of sensory and motor cortical input on striatal circuitry and choice behavior. Curr. Biol. 2019, 29, 1313-1323. [CrossRef]

35. Loporto, M.; Holmes, P.S.; Wright, D.J.; McAllister, C.J. Reflecting on mirror mechanisms: Motor resonance effects during action observation only present with low-intensity transcranial magnetic stimulation. PLoS ONE 2013, 8, e64911. [CrossRef]

36. Zschorlich, V.R.; Köhling, R. How thoughts give rise to action-conscious motor intention increases the excitability of target-specific motor circuits. PLoS ONE 2013, 8, e83845. [CrossRef]

37. Bruton, A.M.; Mellalieu, S.D.; Shearer, D.A. Observation as a method to enhance collective efficacy: An integrative review. Psychol. Sport Exerc. 2016, 24, 1-8. [CrossRef]

38. Gueugneau, N.; Bove, M.; Ballay, Y.; Papaxanthis, C. Interhemispheric inhibition is dynamically regulated during action observation. Cortex 2016, 78, 138-149. [CrossRef]

39. Schubert, M.; Curt, A.; Jensen, L.; Dietz, V. Corticospinal input in human gait: Modulation of magnetically evoked motor responses. Exp. Brain Res. 1997, 115, 234-246. [CrossRef]

40. Holl, N.; Zschorlich, V.R. Neural control of joint stability during a ballistic force production task. Exp. Brain Res. 2011, 210, 229-242. [CrossRef]

41. Zschorlich, V.R. Digital filtering of emg-signals. Electromyogr. Clin. Neurophysiol. 1989, 29, 81-86. [PubMed]

42. Merletti, R.; Hermens, H. Detection and conditioning of the surface emg signal. Electromyography 2004, 107-131. [CrossRef]

43. Fadiga, L.; Fogassi, L.; Pavesi, G.; Rizzolatti, G. Motor facilitation during action observation: A magnetic stimulation study. J. Neurophysiol. 1995, 73, 2608-2611. [CrossRef]

44. Stinear, C.M.; Byblow, W.D. Motor imagery of phasic thumb abduction temporally and spatially modulates corticospinal excitability. Clin. Neurophysiol. 2003, 114, 909-914. [CrossRef]

45. Kumru, H.; Albu, S.; Rothwell, J.; Leon, D.; Flores, C.; Opisso, E.; Tormos, J.M.; Valls-Sole, J. Modulation of motor cortex excitability by paired peripheral and transcranial magnetic stimulation. Clin. Neurophysiol. 2017, 128, 2043-2047. [CrossRef]

46. Behrens, M.; Husmann, F.; Mau-Moeller, A.; Schlegel, J.; Reuter, E.M.; Zschorlich, V. Neuromuscular properties of the human wrist flexors as a function of the wrist joint angle. Front. Bioeng. Biotechnol. 2019, 7, 181.

47. Longo, M.R.; Schüür, F.; Kammers, M.P.; Tsakiris, M.; Haggard, P. What is embodiment? A psychometric approach. Cognition 2008, 107, 978-998. [CrossRef]

48. Stein, B.E.; Meredith, M.A. The Merging of the Senses; The MIT Press: Cambridge, MA, USA, 1993.

49. Van Beers, R.J.; Sittig, A.C.; van der Gon, J.J.D. Integration of proprioceptive and visual position-information: An experimentally supported model. J. Neurophysiol. 1999, 81, 1355-1364. [CrossRef]

50. Hay, J.C.; Pick, H.L.; Ikeda, K. Visual capture produced by prism spectacles. Psychon. Sci. 1965, 2, 215-216. [CrossRef]

51. Shams, L.; Kim, R. Crossmodal influences on visual perception. Phys. Life Rev. 2010, 7, 269-284. [CrossRef]

52. Guerraz, M.; Provost, S.; Narison, R.; Brugnon, A.; Virolle, S.; Bresciani, J.P. Integration of visual and proprioceptive afferents in kinesthesia. Neuroscience 2012, 223, 258-268. [CrossRef]

53. Maravita, A.; Spence, C.; Driver, J. Multisensory integration and the body schema: Close to hand and within reach. Curr. Biol. 2003, 13, R531-R539. [CrossRef]

54. Giroux, M.; Barra, J.; Zrelli, I.E.; Barraud, P.-A.; Cian, C.; Guerraz, M. The respective contributions of visual and proprioceptive afferents to the mirror illusion in virtual reality. PLOS ONE 2018, 13, e203086. [CrossRef]

55. Stinear, C.M.; Byblow, W.D.; Steyvers, M.; Levin, O.; Swinnen, S.P. Kinesthetic, but not visual, motor imagery modulates corticomotor excitability. Exp. Brain Res. 2006, 168, 157-164. [CrossRef]

56. Alaerts, K.; Swinnen, S.P.; Wenderoth, N. Interaction of sound and sight during action perception: Evidence for shared modalitydependent action representations. Neuropsychologia 2009, 47, 2593-2599. [CrossRef]

57. Strick, P.L.; Preston, J.B. Two representations of the hand in area 4 of a primate. I. Motor output organization. J. Neurophysiol. 1982, 48, 139-149. [CrossRef]

58. Dum, R.P.; Strick, P.L. Motor areas in the frontal lobe: The anatomical substrate for the central control of movement. In Motor Cortex in Voluntary Movements: A Distributed System for Distributed Functions; CRC Press: Boca Raton, FL, USA, 2005 ; pp. 3-47.

59. Ladda, A.M.; Wallwork, S.B.; Lotze, M. Multimodal sensory-spatial integration and retrieval of trained motor patterns for body coordination in musicians and dancers. Front. Psychol. 2020, 11, 3201. [CrossRef]

60. Gruber, M.; Linnamo, V.; Strojnik, V.; Rantalainen, T.; Avela, J. Excitability at the motoneuron pool and motor cortex is specifically modulated in lengthening compared to isometric contractions. J. Neurophysiol. 2009, 101, 2030-2040. [CrossRef]

61. Mouthon, A.; Ruffieux, J.; Wälchli, M.; Keller, M.; Taube, W. Task-dependent changes of corticospinal excitability during observation and motor imagery of balance tasks. Neuroscience 2015, 303, 535-543. [CrossRef] 
62. Duchateau, J.; Enoka, R.M. Neural control of lengthening contractions. J. Exp. Biol. 2016, 219, 197-204. [CrossRef]

63. Calvert, G.; Spence, C.; Stein, B.E. The Handbook of Multisensory Processes; MIT Press: Cambridge, MA, USA, 2004.

64. Keysers, C.; Gazzola, V. Expanding the mirror: Vicarious activity for actions, emotions, and sensations. Curr. Opin. Neurobiol. 2009, 19, 666-671. [CrossRef]

65. Carrillo, M.; Han, Y.; Migliorati, F.; Liu, M.; Gazzola, V.; Keysers, C. Emotional mirror neurons in the rat's anterior cingulate cortex. Curr. Biol. 2019, 29, 1301-1312. [CrossRef]

66. Barraclough, N.E.; Xiao, D.; Baker, C.I.; Oram, M.W.; Perrett, D.I. Integration of visual and auditory information by superior temporal sulcus neurons responsive to the sight of actions. J. Cogn. Neurosci. 2005, 17, 377-391. [CrossRef]

67. Dahl, C.D.; Logothetis, N.K.; Kayser, C. Spatial organization of multisensory responses in temporal association cortex. J. Neurosci. 2009, 29, 11924-11932. [CrossRef]

68. Kaplan, J.T.; Iacoboni, M. Multimodal action representation in human left ventral premotor cortex. Cogn. Process. 2007, 8, 103-113. [CrossRef]

69. Nakashita, S.; Saito, D.N.; Kochiyama, T.; Honda, M.; Tanabe, H.C.; Sadato, N. Tactile-visual integration in the posterior parietal cortex: A functional magnetic resonance imaging study. Brain Res. Bull. 2008, 75, 513-525. [CrossRef]

70. Wallace, M.T.; Wilkinson, L.K.; Stein, B.E. Representation and integration of multiple sensory inputs in primate superior colliculus. J. Neurophysiol. 1996, 76, 1246-1266. [CrossRef]

71. Murray, M.M.; Wallace, M.T. The Neural Bases of Multisensory Processes; CRC Press: Boca Raton, FL, USA, 2011.

72. Calvert, G.A.; Campbell, R.; Brammer, M.J. Evidence from functional magnetic resonance imaging of crossmodal binding in the human heteromodal cortex. Curr. Biol. 2000, 10, 649-657. [CrossRef]

73. Parker, P.R.; Brown, M.A.; Smear, M.C.; Niell, C.M. Movement-related signals in sensory areas: Roles in natural behavior. Trends Neurosci. 2020, 43, 581-595. [CrossRef]

74. Meredith, M.A.; Stein, B.E. Visual, auditory, and somatosensory convergence on cells in superior colliculus results in multisensory integration. J. Neurophysiol. 1986, 56, 640-662. [CrossRef]

75. Meredith, M.; Wallace, M.; Stein, B. Visual, auditory and somatosensory convergence in output neurons of the cat superior colliculus: Multisensory properties of the tecto-reticulo-spinal projection. Exp. Brain Res. 1992, 88, 181-186. [CrossRef]

76. Rizzolatti, G.; Sinigaglia, C. The mirror mechanism: A basic principle of brain function. Nat. Rev. Neurosci. 2016, 17, 757. [CrossRef]

77. Rizzolatti, G.; Cattaneo, L.; Fabbri-Destro, M.; Rozzi, S. Cortical mechanisms underlying the organization of goal-directed actions and mirror neuron-based action understanding. Physiol. Rev. 2014, 94, 655-706. [CrossRef]

78. Fogassi, L.; Gallese, V.; Fadiga, L.; Luppino, G.; Matelli, M.; Rizzolatti, G. Coding of peripersonal space in inferior premotor cortex (area f4). J. Neurophysiol. 1996, 76, 141-157. [CrossRef]

79. Rizzolatti, G.; Matelli, M.; Pavesi, G. Deficits in attention and movement following the removal of postarcuate (area 6) and prearcuate (area 8) cortex in macaque monkeys. Brain 1983, 106, 655-673. [CrossRef] 